\title{
Inter-brain Synchronization in the Practice of Tibetan Monastic Debate
}

\author{
Marieke K. van Vugt ${ }^{1,2}$ (D) Joshua Pollock ${ }^{3}$. Bryce Johnson ${ }^{4} \cdot$ Kalden Gyatso $^{5} \cdot$ Ngawang Norbu $^{5} \cdot$ Thabkhe Lodroe $^{5}$. \\ Thupten Gyaltsen $^{6}$ - Lobsang Phuntsok ${ }^{5}$. Jampa Thakchoe ${ }^{5}$. Jampa Khechok ${ }^{5}$. Jampa Lobsang ${ }^{5}$. Lobsang Tenzin ${ }^{5}$. \\ Jampa Gyaltsen ${ }^{5} \cdot$ Amir Moye $^{7} \cdot$ David M. Fresco $^{8}$
}

Published online: 21 February 2020

(C) The Author(s) 2020

\begin{abstract}
Objectives Although mindfulness meditation is the familiar and researched form of mental training derived from Buddhism, it represents but one form of practice. Monastic debate is an interactive and dyadic analytical meditation practice that originates from the Tibetan Buddhist tradition where monastics seek to jointly deepen their understanding of complicated philosophical issues. To date, monastic debate and analytic meditation have yet to be examined in the context of scientific investigation.

Methods In the current study, we examined the neural correlates of this analytical meditation practice by means of hyperscanning electroencephalography, a method well-suited for examining social interactions.

Results Consistent with the idea that analytical meditation helps to train concentration, we observed that over the course of the debate, mid-frontal theta oscillations - a correlate of absorption-increased significantly. This increase was stronger for more experienced monks as compared with monks at the beginning of their education. In addition, we found evidence for increases in synchrony in frontal alpha oscillations between paired debaters during moments of agreement as compared with disagreement on a set of premises.

Conclusions Together, these findings provide an initial understanding of Tibetan monastic debate and analytical meditation using neuroscientific methods.
\end{abstract}

Keywords Hyperscanning $\cdot$ Monastic debate $\cdot$ Tibetan Buddhism $\cdot$ Meditation $\cdot$ Concentration $\cdot$ Analytical meditation

Electronic supplementary material The online version of this article (https://doi.org/10.1007/s12671-020-01338-1) contains supplementary material, which is available to authorized users.

Marieke K. van Vugt

m.k.van.vugt@ rug.nl

1 Institute of Artificial Intelligence \& Cognitive Engineering, University of Groningen, Groningen, Netherlands

2 Bernoulli Institute of Mathematics, Computer Science \& Artificial Intelligence, Nijenborgh 9, 9747 AG Groningen, The Netherlands

3 Department of Sociology, Kent State University, Kent, OH, USA

4 Science for Monks, Palo Alto, CA, USA

5 Sera Jey Monastic University, Bylakuppe, India

6 Library of Tibetan Works and Archives, Dharamsala, India

7 Department of Psychology, University of Berne, Bern, Switzerland

8 Department of Psychological Sciences, Kent State University, Kent, OH, USA
Although mindfulness has seen a meteoric rise in attention and investigation within the scientific discourse, meditation is far from a monolithic practice even within the Buddhist tradition (e.g., Dahl et al. 2015). To date, neuroscientific and psychological investigations of meditation have emphasized the clinical intervention of mindfulness meditation (Kabat-Zinn 2003; Kuyken et al. 2015), together with different variants of concentration meditation and awareness meditation practiced by predominantly Western practitioners (Lutz et al. 2008). Western science has also recently begun to investigate the basic and clinical facets of compassion practices (Desbordes et al. 2012; Lutz et al. 2009; Pace et al. 2013). A commonality of all these researched forms of meditation is that they are practiced independently, and thus, are amenable to investigation using similar scientific methodology. However, concentrative and compassion meditation reflect only a small sampling of the many contemplative practices that derive from Buddhism. Many more contemplative practices have yet to 
be investigated using rigorous scientific methodology (van Vugt et al. 2019).

Monastic debate has been practiced in many Tibetan monasteries and nunneries, and especially within the Gelug tradition of Tibetan Buddhism. This current form of Tibetan monastic debate was developed in the twelfth century by Chapa Chökyi Senge (Liberman 2007, p. 51). Monastic debate is a form of analytical meditation that complements meditation practices intended to stabilize the mind via focus on a single object (such as mindfulness of the breath). In contrast to stabilizing meditation practices that calm the mind, the stated objective of analytical meditation is to develop insight into the causes and conditions of subjective experience to assist the practitioner uproot suffering, and in turn, to achieve more lasting happiness by eradicating destructive emotions (such as anger) and to develop beneficial emotions (such as compassion).

At a Buddhist monastic university, analytical meditation is preceded by memorization of relevant philosophical texts, which provide the material for the contemplations, and the topic that is utilized during monastic debate (Dreyfus 2003). Debate may serve several functions: to learn; to clear up doubts; to develop critical thinking skills; to acquire a longlasting, holistic and comprehensive understanding of some topic; and to increase compassion and gentleness (Perdue 2014; van Vugt et al. 2019).

The dyadic practice of debate consists most often of a dialectical interaction between a "challenger" and a "defender" (Dreyfus 2003; Liberman 2015; Perdue 1992), although in some instances, there can be multiple challengers and defenders. In their collaborative interaction, the defender is bound to maintain a consistent intellectual position, whereas the challenger is guiding the defender to see different angles on the argument and to think more clearly. More specifically, the role of the challenger is to find inconsistencies in the reasoning of the defender and to try to disprove what the defender says, whereas the role of the defender is to parry arguments posed by the challenger and avoid adopting untenable logical positions. The debate is accompanied by a specific physical form, in which the challenger is standing, towering over the defender, who is sitting on the ground (Fig. 1). Standing is said to enhance the speed and clarity of thinking. Moreover, remaining physically active allows the monks to maintain the debate over a longer period of time (Dreyfus 2003). Appendix $\mathrm{S} 3$ provides more details about the debate format and Appendix S1 provides transcripts of two sample debates.

Debate is an integral component of Tibetan monastic training. Monastics undergo a program of up to 25 years of education and commonly practice debate for about $5 \mathrm{~h}$ per day (see Appendix S2 for more details about the study program) to help cultivate cognitive and emotional skills. First, debate motivates participants to strongly develop their memorization skills. Monastics in our interviews report that they realize

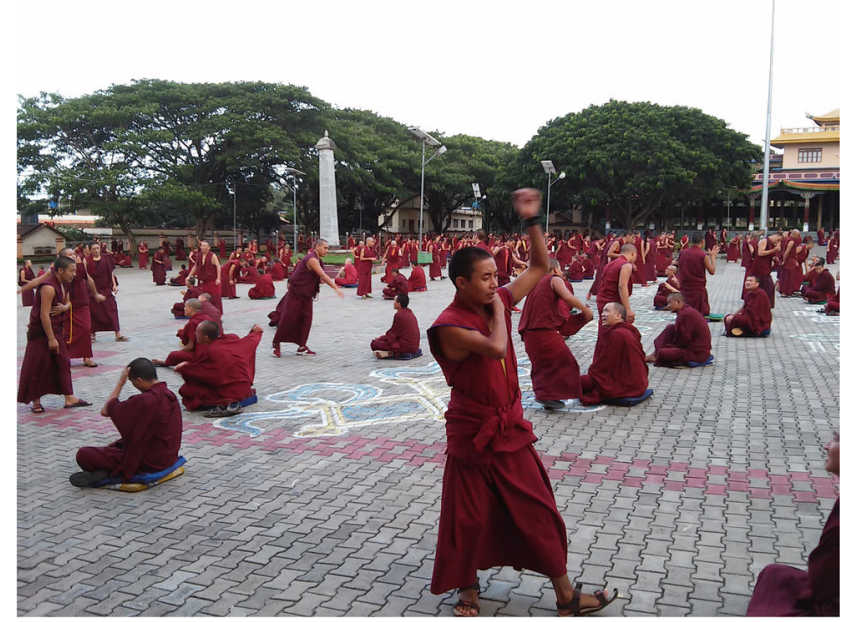

Fig. 1 Typical monastic debate at Sera Jey monastery in India. Debate is a dyadic interaction between a challenger (standing) and a defender (seated) in which the two debaters try to clarify their reasoning

early on in their debate training that failing to memorize the text relevant to a particular debate results in an unfavorable outcome. Second, participating in debate may also cultivate one's reasoning ability, given the frequency and intensity of the practice. Monastic debate further has a strong social component, because knowledge is continually shared and tested inter-subjectively. It is therefore likely that monastics develop strong skills for assessing their partner's mental and emotional states, to allow them to probe their weak points. Moreover, debate likely involves the cultivation of emotion regulation skills, because monastics have told us that despite the debate's stressful situation that can sometimes include teasing and insults, it is critical to not lose composure or become angry, because that impairs the ability to think clearly.

To examine the process of debate in more detail, electroencephalography (EEG) investigations of this practice are needed that leverage what we know about the role of different brain oscillations in cognition as well as phenomenological descriptions by the monastic part of the team. Brain oscillations are useful measures because in contrast to event-related potentials, they are less strictly time-locked to particular events of interest, and thus reflect useful candidates for analyzing the real-world situation of monastic debate, in which there is a lack of clarity on the temporal demarcation of events that occur. Brain oscillations have been associated with a wide range of cognitive functions (see Buzsáki 2006, for a comprehensive overview). For example, mid-frontal 4-9 Hz theta oscillations have been associated with attention, absorption, and cognitive control (e.g., Cavanagh et al. 2010). Theta oscillations in predominantly parieto-temporal locations are associated with accumulating and comparing information (e.g., van Vugt et al. 2012) as well as memory encoding and retrieval (e.g., Sederberg et al. 2003). Alpha oscillations (10$14 \mathrm{~Hz}$ ) have been associated with idling and inhibition (Händel et al. 2010; Pfurtscheller et al. 1996). Beta oscillations 
(14-28 Hz) have most frequently been associated with motor activity (Brovelli et al. 2004). Faster gamma oscillations (28$48 \mathrm{~Hz}$ ) have most reliably been associated with focused attention (Bauer et al. 2006; Hoogenboom et al. 2006).

Inspired by intense discussions between the monastics and scientists, two processes are of particular interest: the development of neural correlates of absorption over the course of the debate session, and the changes in inter-brain synchrony associated with accepting the same premises (agree) and holding different positions in relation to the topic (disagree). The voluntary sustaining of attention, in particular in the context of meditation, has frequently been associated with frontal midline theta oscillations (Ishii et al. 2014) that are thought to arise from medial prefrontal areas and anterior cingulate cortex (Ishii et al. 1999). For example, Aftanas and Golocheikine (2001) found that during internally directed attention in meditation practice there was an increase in mid-frontal theta waves. This finding was recently replicated by Brandmeyer and Delorme (2018) in a sample of practitioners of Himalaya Yoga, a focused attention meditation practice focusing on a mantra. Some studies have additionally associated occipital alpha oscillations with sustained attention (Braboszcz and Delorme 2011; Makeig and Jung 1995), but this is likely reflecting passive fatiguerelated reductions in attention rather than the process of actively sustaining attention (Clayton et al. 2015).

The degree of agreement between two debaters can be measured by a novel method for investigating interindividual cognitive processes, the simultaneous recording of neuroelectric activity in the brain known as "EEG hyperscanning," which has been utilized successfully to quantify neural synchronization with high temporal precision (Dumas et al. 2010; Lindenberger et al. 2009; Pfurtscheller and Lopes Da Silva 1999). Synchronization between the brains of two different individuals has been observed in several contexts, brain areas, and frequency bands. For example, in a prisoner's dilemma task, Babiloni et al. (2007) demonstrated increased inter-brain synchronization in the alpha band when the players were cooperating rather than defecting. Inter-brain synchronization is also enhanced during diverse situations such as joint musical improvisation (Müller et al. 2013), successful therapy interventions (Koole and Tschacher 2017), and in cooperating relative to working separately when pilots are orchestrating a flight take-off (Astolfi et al. 2011). In a classroom situation, Dikker et al. (2017) also found that when students paid more attention, their brains were more synchronized with one another than when they did not pay as much attention; and brains were more synchronized between students and teachers that liked each other.

In the present study, we examined several facets of monastic debate using a combination of live and videotaped coding as well continuous EEG recording of monastics as they engaged in debate. First, we sought to assess the degree of agreement by comparing inter-brain synchronization and predicted larger synchronization during periods of self-reported agreement as compared with periods of disagreement. We further hypothesized that their years of monastic experience would moderate the magnitude of absorption and inter-brain synchronization such that it would be more prominent with longer monastic training. Our second area of inquiry was absorption - the state of being immersed in the meditation practice with completely internally focused attention-by tracking the level of mid-frontal theta power that monastics exhibited during the course of a debate. We predicted that mid-frontal theta would increase over the course of the debate (see also van Vugt et al. 2019).

\section{Method}

\section{Participants}

Participants were drawn from the population of over 1800 monks at Sera Jey Monastery, Bylakuppe, India. Many monastic trainings proceed for 16 years post-high school, and monastics with between 0 and 4 years of training are generally regarded as beginners, monastics with 5 to 12 years of training are generally regarded as intermediate, while monastics with 13 to 16 years of training are generally regarded as experienced. A subset of monastics $(\sim 20 \%)$ continues their formal training in pursuit of advanced degrees, which can continue for an additional 6 to 10 years. Thus, experienced monastics may have as much as 25 years of formal monastic training. Age of entry can vary widely. Once a monk/nun joins the monastery/nunnery, they practice debate on average for $5 \mathrm{~h}$ per day, at least 250 days per year (i.e., $\sim 1250 \mathrm{~h}$ per year), which means that experienced monastics may have an accumulated 16,250 to $20,000 \mathrm{~h}$ of experience with monastic debate.

We performed two studies. Given the study hypotheses, a decision was made to focus recruitment of monk volunteers among two cohorts: beginners versus experienced (approximately 13 in each group for Study 1, and 50 participants in each group for Study 2). In all debates, beginners only debated beginners, while experienced participants only debated experienced participants. The first study was more exploratory to assess the feasibility and refine the methodology of measuring facets of debate with EEG. The participants in this study had between 1 and 22 years of debate experience (mean debate experience for beginners 1 year; mean debate experience for experienced monastics 19.2 years). The participants in this study were between 18 and 44 years of age.

Based on the findings of the first study, we conducted a larger, more controlled second study to replicate these findings. To accrue this sample, an announcement was made by the disciplinarian of the monastery, a senior monk serving in an administrative role and tasked with ensuring that students 
attend classes and follow the monastic curriculum. The disciplinarian told the student body of the study and informed them that the debate topic was on Bodhicitta. "Bodhicitta" is a basic and well-known teaching in the Buddhist tradition and it focuses on altruism and compassion. He encouraged broad participation among the monastics and requested that all participants who volunteered for the study seriously engage with study tasks. A few additional participants were recruited by their science teacher. In hopes of constructing two groups that differed primarily in terms of monastic experience, we endeavored to select students who received top marks in their respective debate classes. For the beginner cohort, we selected participants who had completed their classroom instruction on the topic of Bodhicitta, which is emphasized in year 6 of the curriculum, but studied also before that time. While these are in fact already intermediate level, this level was necessary to allow them to debate about the same topic as the experienced monastics. The average year of experience in the beginners group was 5.3. For the experienced cohort, we selected participants with at least 14 years of debate training, with a mean of 16.1 years. The overall range of experience in this study was 5 to 17 years. The mean age of the beginners was 29.8 , while the mean age of the experienced monastics was 31.8 (total range 19-45).

\section{Procedure}

We focused our investigation on the most common configuration for debate, which involves two monastics: a "challenger" whose role is to put forth a thesis related to canonical Buddhist principles and find contradictions in the logical argument of his opponent, known as the "defender," whose role is to try to interpret the thesis proposed by the challenger and to respond from the perspective of logic and consistency with the canonical texts from Buddhism. Within this configuration, debates can accommodate different formats. We chose to (1) utilize a format called a "counting debate" which outlines the foundation of the debate topic and assesses the quality of the memorization of the text. In particular, the interlocutors are establishing the textual foundation of the debate as well as some ground rules for conducting the debate. This form of debate is quite cooperative. Counting debate is followed by (2) a "logic debate" in which the emphasis lies more strongly on exposing inconsistencies in reasoning. The counting debate is considered by many monks to be easier than the logic debate, and it often serves as a preparation for the logic debate. See Appendix S1 for a sample transcript of a logic and a counting debate.

\section{Informed Consent}

Upon arrival at the testing location, prospective participants were first told about the procedure and we explained to them that participation in the study was entirely voluntary, and they could quit any time without any repercussions. The participants then gave oral informed consent, and the study was conducted in accordance with the declaration of Helsinki. The study protocol was approved by the CETO (Research Ethics Review Committee of the Faculty of Arts of the University of Groningen).

\section{Instructions Given to Debaters}

In Study 1, debater pairs were told they would debate in various configurations, with no specific topic. In Study 2, debater pairs were told that they would be asked to engage first in a 10-min counting debate, followed by a 15 -min logic debate. The order of these debates was chosen because this order is customary in the monastery. The particular topic for the counting debate was "The Definition of Bodhicitta," which was selected given its familiarity to Beginner and Experienced monastics alike. Directly before the counting debate, monastics reviewed their textbook on Bodhicitta for 15 min to refresh their memory of the topic since experienced monks had studied it many years ago.

\section{Conducting the Debates}

After reviewing the textbook (only in Study 2), monastics provided their age, the year they entered the monastery, the year and level of monastic training they had achieved, and then were assigned an identification number that was used to anonymize the data. At that point, monastics were wired with the EEG sensors, performed one counting debate, followed by a logic debate (see Fig. 2 for an impression of the EEG setup). We reversed the roles of the challenger and defender and once again collected data in one counting and one logic debate (in the full study, only 2 counting and 4 logic debates were not reversed). Afterwards, participants were debriefed and a monastic observer completed a debate rating form (only Study 2; see Appendix S4). They were not paid for their participation but were served lunch or dinner following their participation in the study.

While the EEG data were recorded during the debate, a monastic member of the investigative team, fluent in Tibetan and well-versed in monastic debate, was observing the debate and pressed a trigger button whenever he noticed something of interest. In Study 1, he verbalized briefly why he pressed the button, which was noted down by another experimenter and later categorized. In Study 2, we used these verbal descriptions to develop a more complete classification system which is as follows: (1) Match/agree on same point/same opinion, (2) Difference of opinion, (3) Defender has difficulty, (4) Challenger has difficulty, (5) Challenger/defender finds it difficult to remember something, (6) Challenger/defender very focused, (7) Challenger/defender distracted, and (8) 


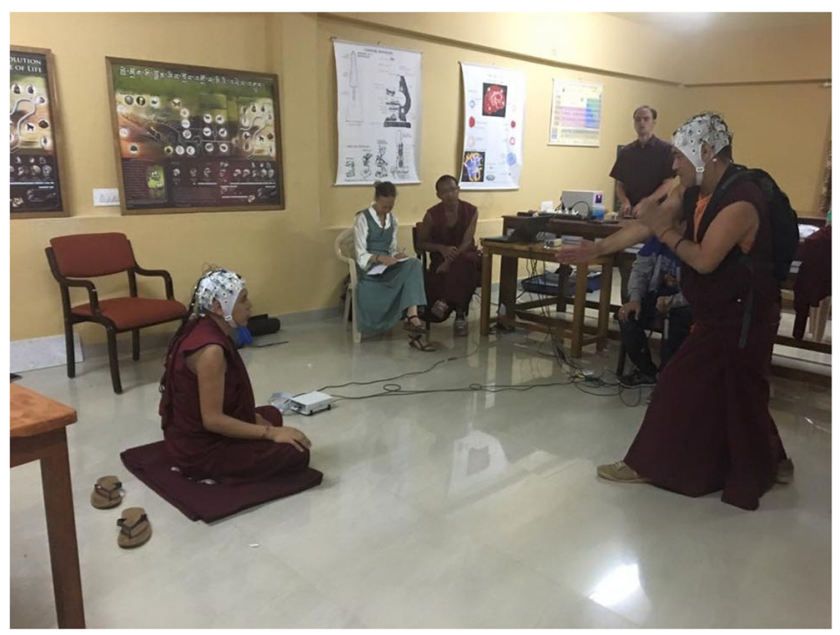

Fig. 2 Example of the EEG setup. One challenger (standing) and one defender (seated) are both wired with an EEG cap. Another monastic is seated behind a computer and presses trigger buttons to create events in the EEG data. Video is also collected of each debate, which was subsequently analyzed with behavioral coding software

Anything else/Other. For this report, we will focus on categories 1 (agreement) and 2 (disagreement). Agreement in the debate was operationally defined as a moment when both debaters accept the same theses and ideas. Disagreement in the debate was defined in two ways: when the defender starts to respond with "why?/disagree", "explain why this is the reason" or "it does not pervade", they enter a period of disagreement; or when the challenger does not accept the definition or explanation offered by the defender.

The rater was extensively briefed on the meaning of the categories. Moreover, the videos of study 2 were each rerated by at least two raters using BORIS video observation software (Friard and Gamba 2016). In contrast to the original ratings, where agreement and disagreement were coded as single moments in time, in BORIS, we could indicate agreement and disagreements as periods with a beginning and end. On the basis of these periods, we divided the EEG signal into 2-s periods, which were labeled as "agreement" when at least half of the raters considered them "agreement," and "disagreement" when at least half of the raters considered them "disagreement." All of the debates were re-rated by at least two raters (in 5 debates, it was rated by 3 raters), who collaborated to find consistent definitions of agreement and disagreement. The challenge with rating these moments of agreement and disagreement is that the rater has to guess what the debater is thinking. Different raters may have had different interpretations. For example, some raters could have pressed the button when there was only a hint at disagreement, while another rater may have waited until they saw a stronger reason. More concretely, a debate proceeds in the following way. A challenger makes a statement, to which the defender can either agree or ask "why?" When the defender asks "why," this implies they doubt the challenger's assertion, but this is not yet enough to define it as a disagreement. After how much arguing, one would define it as disagreement is what is a matter of subjective judgment.

Given this inherent subjectivity in judgments, we sought to measure the degree of consistency between the raters. Since the ratings involve the specification of time intervals, it is not possible to compute inter-rater reliabilities by means of the usual methods such as kappa. Instead, we developed some alternative metrics. Approximately $50 \%$ of the original ratings fell in an agreement/disagreement interval identified by at least one of the new raters, and approximately $20 \%$ of the original ratings fell in an interval identified by all new raters. There were rare cases where one rater thought of a time interval as reflecting agreement, while another rater judged it as being disagreement. This occurred in 7 out of the 54 debates of study 2 , and comprised $0.7 \%$ of the rated time periods. To adjust the analysis for the consistency between raters, we let the probability of including a particular time interval depend on the proportion of raters that felt it reflected agreement/disagreement. In other words: if two out of two raters felt it was an agreement, the time interval was included; if only one of the two felt it was an agreement, the time interval was included with a probability of $50 \%$.

\section{Measures}

\section{EEG Recording}

EEG data were recorded with a 32-channel EEG system (BrainProducts actiCAP) with BrainVision Recorder software, simultaneously for the two monks. The sampling rate was $500 \mathrm{~Hz}$ and the data were recorded with a $0.1-1000 \mathrm{~Hz}$ bandpass filter. Individual channels were adjusted until impedances were below $25 \mathrm{k} \Omega$.

\section{EEG Preprocessing}

For preprocessing, which was performed in with Fieldtrip (Oostenveld et al. 2011), we had separate analysis flows for the examination of theta power over time and synchrony timelocked to specific events indicated by the observing monk (see previous section). Before segmentation, we first applied a 0.5 45-Hz bandpass filter to remove high-frequency muscle activity, followed by an independent component analysis (separately for each of the two recorded participants). We removed any independent component analysis (ICA) that looked suspicious (eye movements, blinks, and muscle artifacts) before transforming back to the original sensor space. For the continuous analysis, we divided the data into 2-s segments, whereas for the time-locked analysis, we segmented the data into segments from 5 to $1 \mathrm{~s}$ prior to each button press. This window was used to account for the reaction time of the observing monastic when reporting an event of interest. 


\section{Data Analyses}

Most of the data analysis was carried out in Matlab by means of the Fieldtrip toolbox (Oostenveld et al. 2011). The EEG data were frequency-transformed by means of a convolution with a Hanning taper on a set of linearly spaced frequencies with a four-cycle window length. Before averaging over the different frequencies within a frequency band, we logtransformed the oscillatory power. We identified the theta frequency as $4-9 \mathrm{~Hz}$, and the alpha frequency as $9-14 \mathrm{~Hz}$ (van Vugt et al. 2007). Mid-frontal theta activity was examined in the usual Fz channel (Doppelmayr et al. 2008; Ishihara and Yoshii 1972). For each individual and each debate, we then fitted a linear regression line to the change in oscillatory power over time to assess the degree of rise over the debate. The slopes of two participants in Study 1 were more than four standard deviations outside the distribution of slopes across participants, and therefore removed from the data analysis.

For the analysis of inter-brain synchrony, we also convolved the EEG with four-cycle Hanning tapers in the frequency band of interest (9-14 Hz alpha). We then computed the phase at each moment in time and assessed the magnitude of the within-trial synchrony between the corresponding channels (Cohen 2014). We compared this trial-averaged synchrony estimate between the different types of debates and different groups of participants by means of linear mixed effects models (Pinheiro and Bates 2009). The advantage of using linear mixed effects models is that they are more robust to violations of independence between observations and different sample sizes for the different cells in the design (Baayen et al. 2008), as we also have in some of our datasets. Moreover, linear mixed effects models have larger statistical power and lead to fewer false discoveries than conventional ANOVA (Baayen et al. 2008; Bolker et al. 2009). We used the linear mixed effects models implemented in R's lme4 package.

Because both inter-brain synchronization and frontal midline theta can be affected by aging (Cummins and Finnegan 2007; Kardos et al. 2014; Tóth et al. 2014; van de Vijver et al. 2014), we regressed out age from inter-brain synchronization and frontal midline theta before running our linear mixed effects model of interest. Results do not change qualitatively between the statistical models that correct for age and those that do not.

In addition to reporting classical statistics, we also include Bayes Factors. The advantage of Bayes Factors is they do not just indicate the presence or absence of a significant effect, but also indicate how much evidence there is, both for or against the null hypothesis. In the results, Bayes Factors are always denoted as Bayes Factors in favor of the alternative hypothesis, against the null, and prefixed with " $\mathrm{BF}_{10}$." Using these conventions, Bayes Factors larger than three indicate substantial evidence in favor of the alternative hypothesis, while Bayes Factors larger than 10 indicate strong evidence in favor of the alternative hypothesis (Jeffreys 1998; Wagenmakers et al. 2017). Bayes Factors smaller than 0.3 (1/3) indicate substantial evidence in favor of the null hypothesis (and against the alternative hypothesis), and Bayes Factors smaller than 0.1 indicate substantial evidence in favor of the null hypothesis. In the whole manuscript, we used the default prior. We used the BayesFactor package in R for the Bayes Factors (Morey and Rouder 2018).

Movement artifacts are a significant concern when performing EEG studies on moving participants. We addressed these problems in several ways. First, we used an active electrode system, which avoided artifacts arising from the dangling movement of the wires. Second, we used independent component analysis to remove components reflecting these movement artifacts, which have a time course very different from normal EEG (and are therefore well-captured by ICA). Third, we low-pass-filtered the data, since movement artifacts tend to show up predominantly at higher frequencies. Supplementary Fig. S1 (Appendix S5) shows a sample EEG trace during the debate, which is representative of the average EEG quality (it is neither the most clean nor the most noisy). As a rough estimate of artifact activity, we also computed the average EEG amplitude and 110-140 $\mathrm{Hz}$ activity (associated with movement) separately for the challenger (who is moving) and the defender (who is seated). Neither average EEG amplitude $\left(t(106)=0.17, B F_{10}=0.21\right)$ nor $110-140 \mathrm{~Hz}$ activity $\left(t(106)=1.43, B F_{10}=0.507\right)$ was different between the challengers and defenders.

\section{Results}

\section{Differences in Inter-brain Synchronization Between Agreement and Disagreement Periods}

Our first hypothesis was that periods in which the debaters were observed to agree on a shared set of premises would be associated with higher inter-brain synchrony than when they express disagreement with one another. We surmised that when the monks agree on a shared set of premises, they are more likely to think similar thoughts, which would increase the chances that their brains are synchronized compared with when the monks have some disagreements. We also predicted that this difference would grow with debate experience.

We initially tested these hypotheses in our exploratory Study 1 . As we predicted, we observed a statistically significant increase in frontal alpha inter-brain synchronization for agreement relative to disagreement (linear mixed effects $\chi^{2}(1)=3.94, p=0.05, B F_{10}=1.14$, Fig. 3). When we look at electrodes that exhibit a significant main effect of experience in the linear mixed effects model (Fig. 4), there was overall smaller inter-brain synchronization with more experience (linear mixed effects $\chi^{2}(1)=7.58, p=0.01, B F_{10}=0.86$ ), and 
Fig. 3 Effects of agreement on inter-brain synchrony. Top row: inter-brain synchronization in the alpha band as a function of agreement/disagreement and experience for the channel showing the largest difference between agreement and disagreement. More experience is indicated with blue-green bars, while less experience is denoted by red bars. Error bars reflect standard error of the mean. Bottom row: significance of the effect of experience for all channels in terms of $p$ value

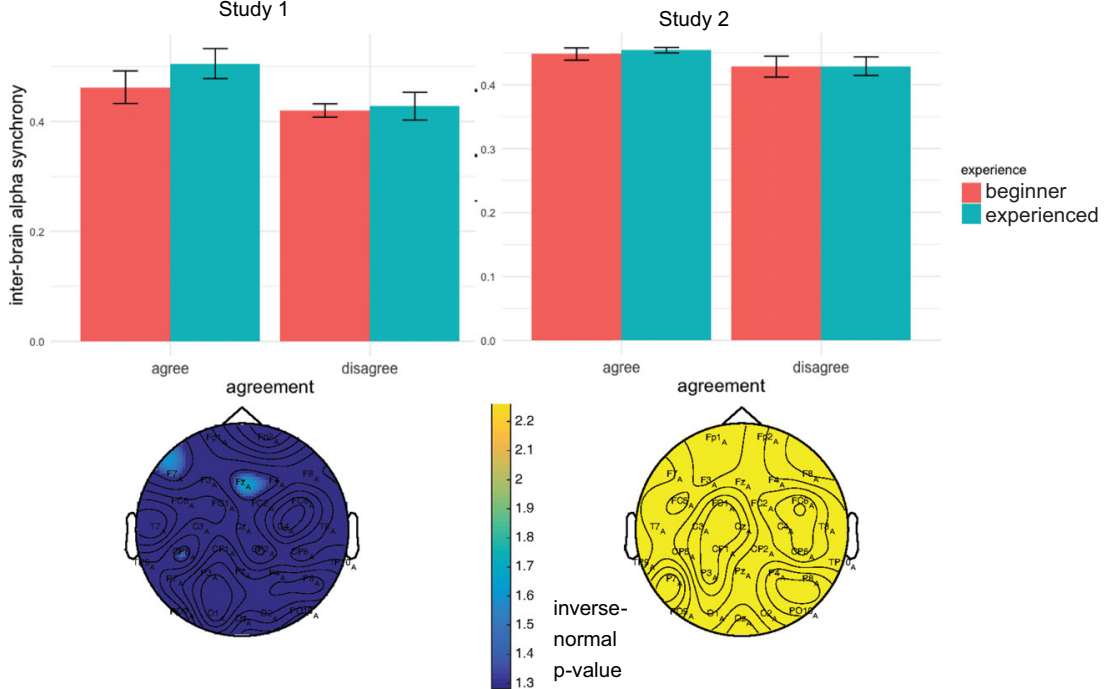

interestingly, for these electrodes that are sensitive to monastic experience in Study 1, inter-brain synchrony is higher for disagree compared to agree periods.

We then examined whether those effects replicated in the second study. In this study, we observed a main effect of agreement on alpha synchrony between the two debaters' brains $\left(\chi^{2}(1)=33.62, p<0.001, B F_{10}>10.000\right.$; see Fig. 3). The topography was more widespread than observed in Study 1, but included also similar frontal electrodes. In contrast to Study 1, there was no effect of monastic experience on brain synchronization in the alpha band $\left(\chi^{2}(1)=2.24, p=0.13, B F_{10}=0.08 ;\right.$ Fig. 4$)$. In Study 2 , there were 27 (out of 32 ) electrodes that demonstrated a significant interaction between agreement and debate experience. The electrode with the strongest effect $\left(\chi^{2}(1)=39.83, p<0.001, B F_{10}=5821.9\right)$ reflected no difference between agreement and disagreement for beginner monks $\left(t(31.8)=-0.52, p=0.604 ; B F_{10}=0.214\right)$; but a small significant difference for experienced monks $\left(t(31.9)=2.40, p=0.022, B F_{10}=2.23\right)$.
Fig. 4 Effects of experience on inter-brain synchrony. Top row: inter-brain synchronization in the alpha band as a function of agreement/disagreement and experience for the channel that showed the largest difference between more and less experience. More experience is indicated with blue-green bars, while less experience is denoted by red bars. Error bars reflect standard error of the mean. Bottom row: significance of the effect of experience as a function of channel, indicated by the $p$ value where yellow color indicates significance

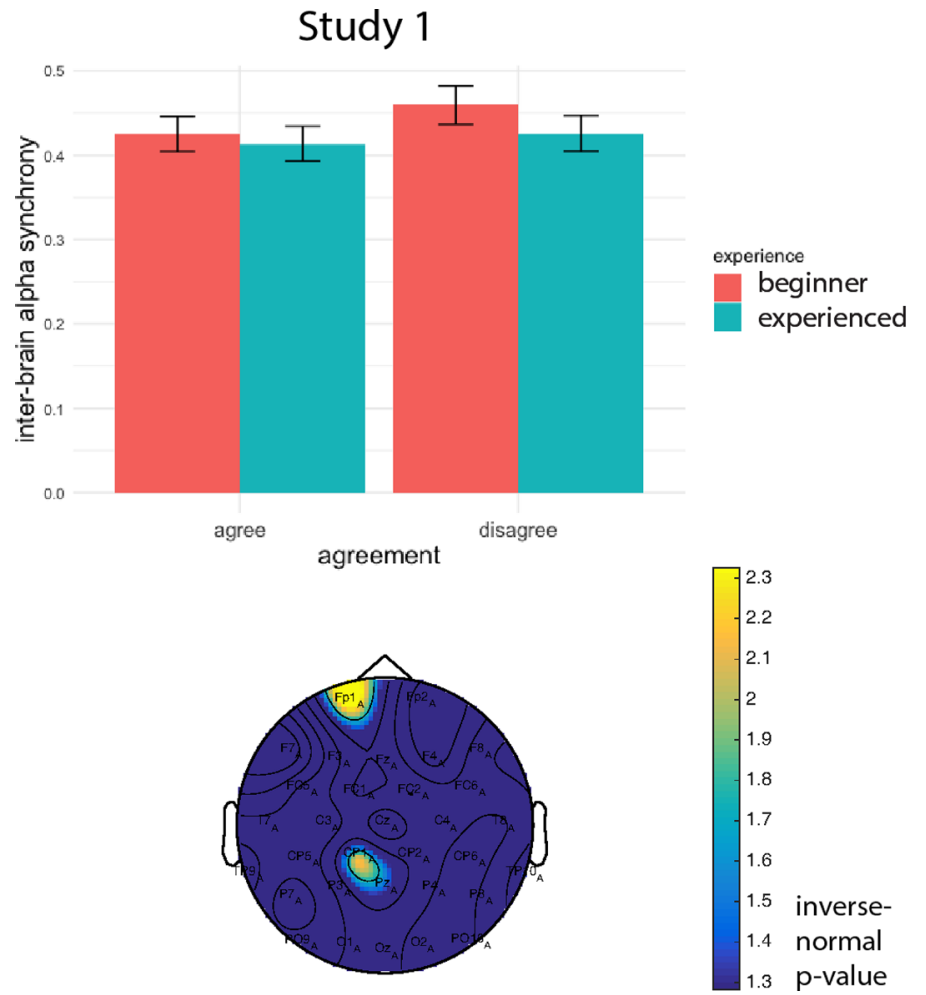




\section{Mid-frontal Theta as a Measure of Absorption}

Our second hypothesis was that monastics' attention becomes more strongly internally directed to the flow of arguments over the course of the debate, and that mid-frontal $4-9 \mathrm{~Hz}$ theta power would increase from the start of the debate until its end as a consequence. Moreover, since this internally directed attention cannot increase indefinitely, the theta power curve should flatten off towards the end of the debate. To test this hypothesis, we examined whether $4-9 \mathrm{~Hz}$ theta power in electrode Fz increased over the course of the full debate.

In Study 1, in which we examined a set of 26 heterogeneous debates, we observed a significant increase in midfrontal theta power over time $(t(51)=4.06, p<0.001$, $B F_{10}=140$; Fig. 5). Even though the top row of this figure seems to suggest that at the end of the debate, theta power drops again, this is an artifact of averaging debates of different lengths (see bottom row of Fig. 5 for time course of theta power that is time-locked to the end of the debate; which does not demonstrate a drop). We used a linear mixed effects model to assess whether the magnitude of the mid-frontal theta slope was moderated by the role of the participant (challenger, defender), or their level of monastic experience (beginning, experienced) or the interaction of these two main effect factors. This linear mixed effects model was performed on the residuals of the theta slopes after age had been regressed out. There was no significant effect of role, that is, we could not tell whether there was a difference between challengers and defenders $\left(\chi^{2}(1)=3.15, p=0.07, B F_{10}=0.81\right)$ but there was there a main effect of experience $\left(\chi^{2}(1)=4.67, p=0.03\right.$, $\left.B F_{10}=2.37\right)$. The interaction of role and experience did not add to the prediction of mid-frontal theta power $\left(\chi^{2}(1)=0.69\right.$, $p=0.40, B F_{10}=2.29$ ).

In this first study consisting of heterogeneous debate dyads, we tried out many theoretically and hypothesis-driven configurations to assess the influence of different factors on the progression of the debate and associated brain activity. First, our monastic collaborators hypothesized that the presence of one's debate teacher would lead the participating monks to take the debate more seriously. Consequently, we predicted that the mid-frontal theta slope would be much steeper for the debate where the teacher was present as an observer, compared with where he was not present. This prediction turned out to be weakly supported by the data. Overall theta power
Fig. 5 4-9-Hz theta oscillatory power increases significantly over the duration of the debate in Study 1. Shown here is average $\mathrm{z}$-scored theta power over time, timelocked to the beginning of the debate (top) and to the end of the debate (bottom). Time zero indicates the beginning of the debate, while the ending time is flexible. If the debate persisted for more than $15 \mathrm{~min}$, the remaining time is cut off from the graph. Gray shading represents a $95 \%$ confidence interval estimated with a loess curve

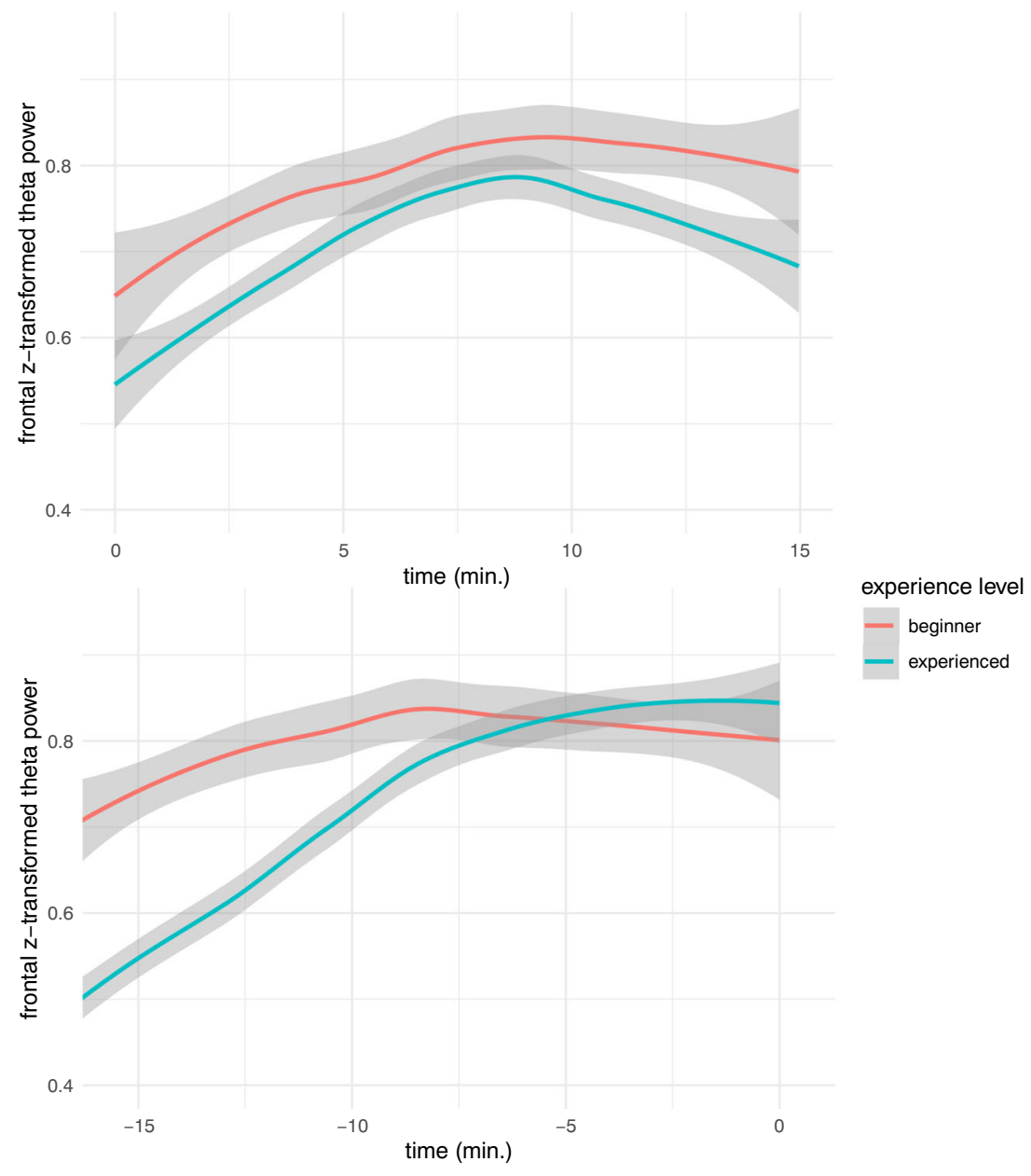


was larger when the teacher was present (linear mixed effects intercept $M=0.089$ ) than when he was not (intercept $M=$ 0.045 ; trend towards a significant interaction between theta power and debate, linear mixed effects $\beta=-0.04, p=0.098$, $B F$ comparing models with and without teacher: 148 ). There was no significant difference in the slopes between the debates with and without a teacher (linear mixed effects interaction $\left.\beta=-0.002, p=0.46, B F_{10}=0.1\right)$. A potential interpretation is that the teacher effect was already occurring due to the novelty of foreign researchers observing the debate with unfamiliar and potentially intimidating equipment.

Monastics usually debate people in their own class, who they know quite well. Monastics we interviewed indicated that when they debated a monastic from a different class, they tended to feel the need to concentrate more so they would be better able to adapt to the unknown and unexpected strategies of their opponent. Consequently, we hypothesized that the slope of mid-frontal theta is larger when monastics are debating colleagues from a different class relative to their own class. We found a highly significant interaction between slope and class $\left(\beta=-0.02, p<0.001, B F_{10}=121\right)$, indicating that the mid-frontal theta slope was larger when debating an interlocutor from different class $(M=0.0334)$ compared with debating an interlocutor from one's own class $(M=0.0128)$. Of course it should be kept in mind that these are only exploratory analyses on a small subset of the data, which need to be replicated before serious conclusions can be drawn.

In Study 2, we sought to replicate our prior findings while using a more controlled, internally reliable debate format (Fig. 6). For instance, in this controlled setting, we elected to keep every debate to the same length and same topic (see the "Method" section). Increasing the number of recorded debates $(N=54)$ provided with more statistical power. Moreover, in this study, all monks did both a logic debate and a counting debate. The monastics hypothesized that the counting debate was much easier and would therefore be associated with less increase in mid-frontal theta activity. As before, we compared beginner with more experienced monastics.

As in Study 1, we observed a significant increase in midfrontal theta over time $\left(t(105)=4.26, p<0.001 B F_{10}=382\right.$; Fig. 5). We then asked whether this increase in mid-frontal theta was larger for more experienced monks than beginner monks, whether it depended on whether they were challenger or defender, and whether it differed between counting and logic debates. We observed a trend towards a significant effect of experience $\left(\chi^{2}(1)=3.58, p=0.058, B F_{10}=1.16\right)$, with a larger increase in theta power for more experienced monks compared with beginner monks (post hoc $t$ test $t=2.58, p=$ $0.011)$. The data did not allow us to adjudicate whether there was a difference between counting and logic debates $\left(\chi^{2}(1)=\right.$ $\left.1.19, p=0.27, B F_{10}=0.44\right)$. There was a weak but significant interaction between experience and the debate type $\left(\chi^{2}(1)=\right.$ $\left.4.13, p=0.04, B F_{10}=1.94\right)$. The interaction indicated that for more experienced monks, there was an increase in theta over time for both counting and logic debates (post hoc $t$ test comparing counting and logic debates, $t(50.8)=-0.22, p=0.828$, $B F_{10}=0.157$ ), but for beginner monks, there was only an increasing theta slope for the logic debates, while the slope remained relatively flat during counting debates (post hoc $t$ test comparing slopes of logic and counting debates, $t(49.2)=$ 2.01, $p=0.049, B F_{10}=0.98$ ).

Because in this study, our data were more reliable than in Study 1, we further explored whether the mid-frontal theta effect was possibly larger in other electrodes than Fz. Figure 7 indicates that the strongest theta slopes occurred slight to the right of Fz in channel F4 (the yellow color indicates $t$ values that are larger than 3.0, and thereby surpass a

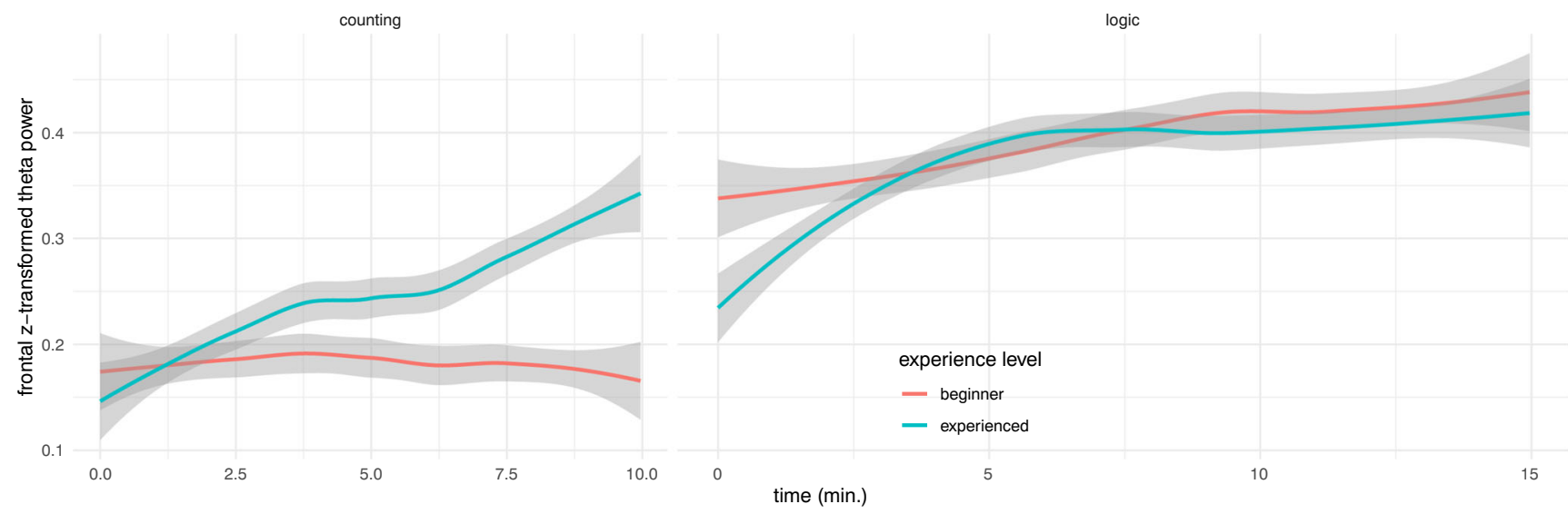

Fig. $6 \quad 4-9-\mathrm{Hz}$ theta oscillations increase significantly over the duration of the debate in Study 2, separately for beginners and experienced monks in logic debates (right). Left column shows that for counting debates, the increase is only visible for experienced monks. Shown here is average $z$ - scored theta power over time, where time zero indicates the start of the debate. Logic debates have a 15-min duration, while counting debates have a 10 -min duration. Gray shading indicates the $95 \%$ confidence interval 
Fig. 7 Topographical plot of theta slope for all channels, separately for the counting and the logic debates. More yellow colors indicate a more positive slope (color indicates the value of the $t$ statistic on the slopes). A $t$ value of 1.66 corresponds to a $p$ value of 0.05 ; a $t$ value of 3.0 corresponds to a $p$ value of 0.001 , which is equivalent to a $p$ value threshold of 0.05 that is Bonferroni-corrected across the number of channels

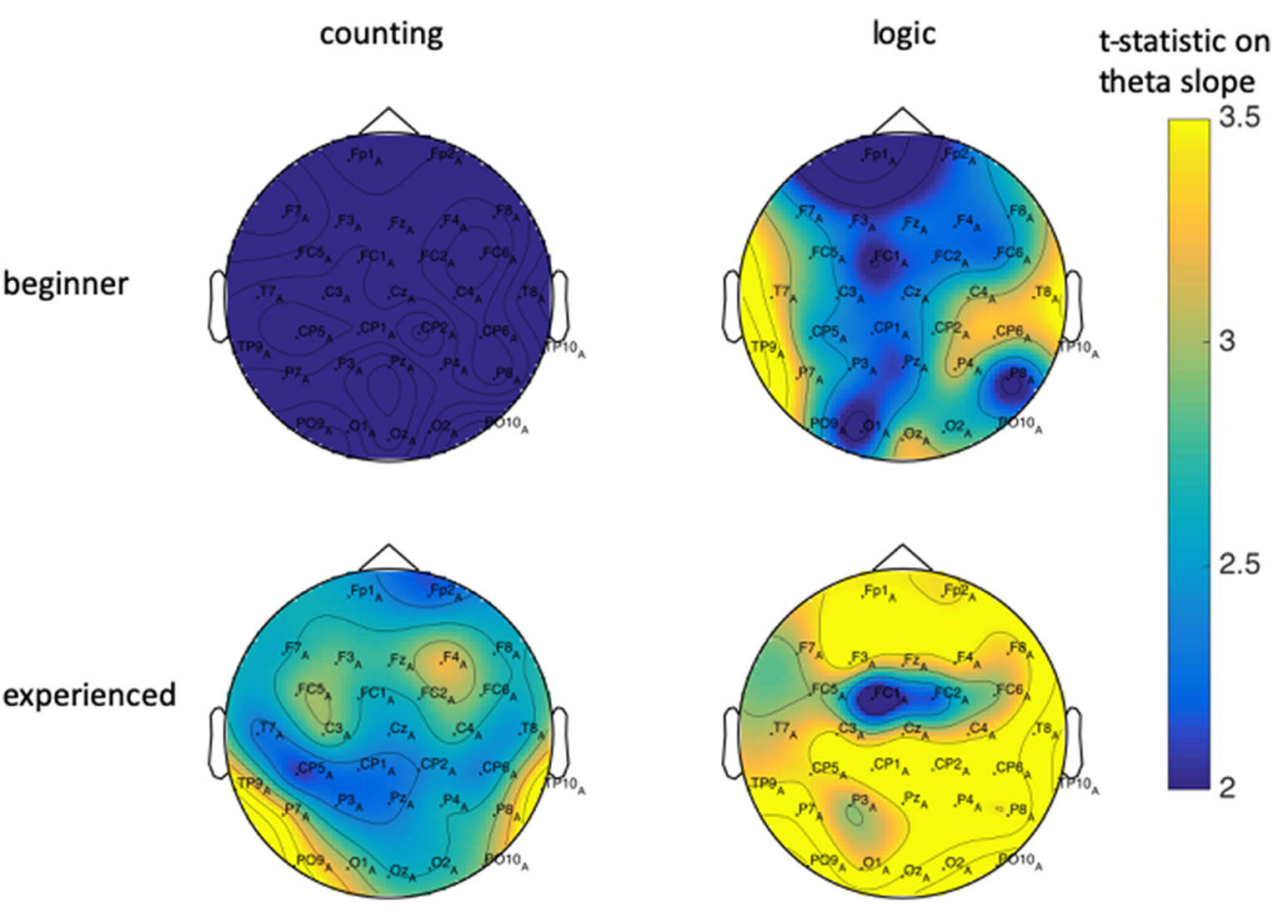

Bonferroni-corrected $p$ value threshold of 0.05 ). When we repeated the analysis in channel $\mathrm{F} 4$, we found that there was a main effect of experience $\left(\chi^{2}(1)=6.83, p=0.009, B F_{10}=\right.$ 3.72 ), and a significant interaction between experience and whether the debate was a counting or a logic debate $\left(\chi^{2}(1)=6.99, p=0.008, B F_{10}=7.06\right)$. As before, the interaction indicated that for more experienced monks, there was an increasing theta slope for both counting and logic debates (post hoc $t$ test indicates no difference; $t(47.2)=-0.89, p=$ $0.377, B F_{10}=0.22$ ), but for beginner monks, there was only a significant theta slope for the logic debates (post hoc $t$ test shows higher slope for logic debates; $t(49.5)=2.32, p=$ $0.024, B F_{10}=1.75$ ). There was no main effect of logic vs. counting debates $\left(\chi^{2}(1)=0.51, p=0.48, B F_{10}=0.30\right)$.

\section{Correlation Between Mid-frontal Theta Power and Inter-brain Synchronization}

Finally, we asked whether, when a person has an overall steeper theta increase over the debate (potentially reflecting increased internally directed attention), he is also more focused on the other person he is debating with. This can be operationalized as a correlation between the mid-frontal theta slope and the average inter-brain frontal alpha synchronization for a particular debate.

In Study 1, there was a significant positive correlation between overall debate theta and strength or inter-brain synchrony $\left(r(51)=0.34, p=0.015, B F_{10}=3.04\right.$, Fig. 8$)$. The more a person's absorption increases over the course of the debate, the more his brain is also synchronized with other debater in frontal alpha oscillations.
We then examined whether the same relation would be observed in Study 2. We found that neither in logic debates $\left(r(54)=0.016, p=0.91, B F_{10}=0.17\right)$ nor in counting debates $\left(r(47)=-0.15, p=0.32, B F_{10}=0.29\right)$ was there a significant correlation between these variables - in fact, the Bayes Factors indicate that there was some evidence for no correlation.

\section{Discussion}

This study represents an initial neuroscientific investigation of analytical meditation and monastic debate. The results showed that inter-brain synchronization during this non-solitary, interdependent meditation practice changes with the degree of agreement between the debaters. Inter-brain synchrony is a relevant measurement because the type of analytical meditation described in this paper also has a strong social component. Recent work by Engert et al. (2017) has demonstrated that social/inter-dependent forms of meditation, which in their study trained perspective taking and involved dyadic practices reduced the stress response to a significant social stressor. In addition, dyadic meditation caused participants to feel more close to each other (Kok and Singer 2017). This finding may indicate that engaging with another person in a meditative way can have benefits for emotional resilience in daily life situations. Monastic debate too involves the meditative interaction with another person. As such, future research could investigate whether monastic debate, which also fosters social bonding, albeit by way of a more vigorous and antagonistic approach, has similar effects on stress and feelings of closeness. 
Fig. 8 Correlation between midfrontal theta slope and inter-brain frontal alpha synchronization in Study 1 . Each dot reflects an individual in a debate

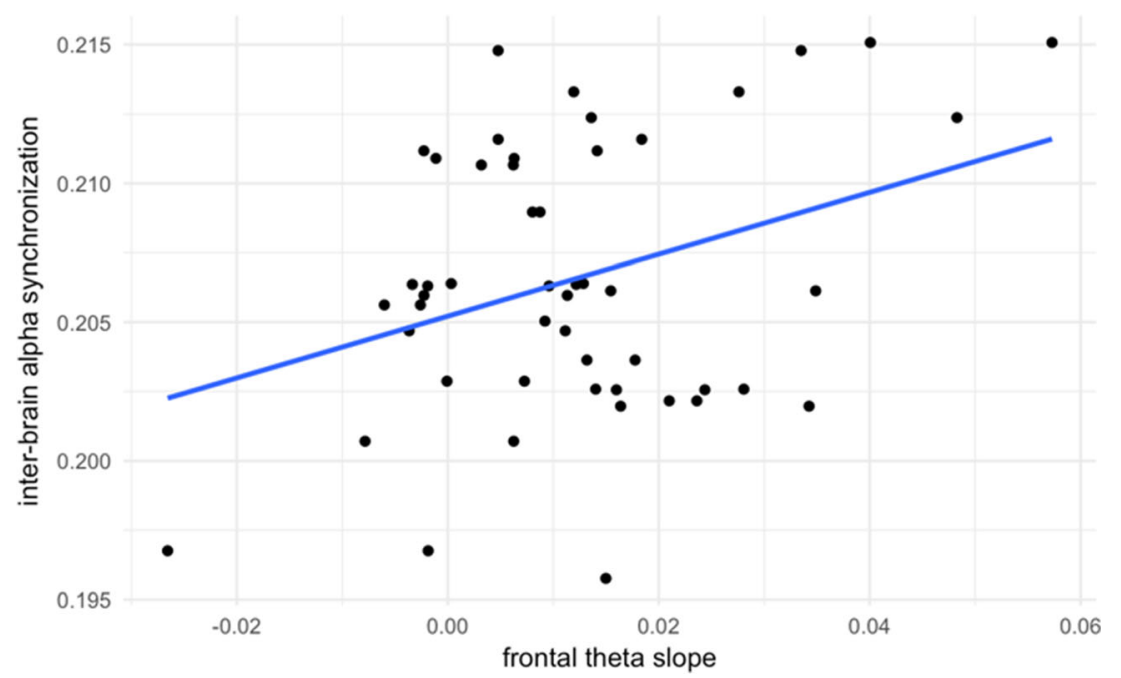

The presented work also furthers knowledge about the role of inter-brain synchrony in cognition more generally. At this point, there is no consensus yet about the exact role of interbrain synchrony, and about whether synchrony in different brain areas and frequencies could have different functions. Some studies found increased inter-brain synchrony at predominantly alpha band frequencies during cooperation (Konvalinka et al. 2014; Toppi et al. 2016). Other studies have focused more on attentional engagement and found that when people are more engaged with the same stimuli and with each other, their brain activity becomes synchronized (using slightly different metrics (Dikker et al. 2017; Ki et al. 2016). In those contexts, inter-brain synchrony may reflect more something akin to joint or shared attention (Lachat et al. 2012). The results reported here suggest a yet more subtle signature of inter-brain synchrony, which was larger when monastics were in agreement on a series of premises, compared with when they differed on the premises they accepted to be true. This suggests that inter-brain synchrony is not only sensitive to what happens at a particular moment, but also information in working memory that participants collect over a longer period of time.

The data showed how across two studies, absorption, as indicated by mid-frontal theta power, increased over the course of the debates. This increase was stronger for more experienced monks as compared with beginner monks, and stronger for the more difficult logic debates than for the counting debates. These findings add to the literature on the neural correlates of meditation that has also shown increases in frontal midline theta during various meditative states (Aftanas and Golocheikine 2001; Kubota et al. 2001). This increase in mid-frontal theta power correlates with meditation experience (Aftanas and Golocheikine 2001; Cahn and Polich 2006). Also, putatively associated with concentration during focused attention meditation are reports of increased long- range temporal correlations in EEG activity (Irrmischer et al. 2018). The current findings are consistent with the idea that monastic debate can be classified as a form of meditation that trains attention, although further behavioral evidence is necessary to back up that claim.

Previous studies of other forms of meditation have not only demonstrated increased in mid-frontal theta, but other frequencies as well. For example, Lutz et al. (2004) observed increased gamma oscillatory power and synchrony compared with baseline during non-referential compassion, an open monitoring practice, and this increase was unique to highly experienced practitioners. Recent work has replicated this gamma increase, extending it by showing that gamma power was also higher in open monitoring meditation compared with focused attention meditation (Fucci et al. 2018). Increased gamma synchrony may be associated more with a sense of openness, broad awareness, and breaking down of the barriers between self and others (Dahl et al. 2015; Josipovic 2014; Lutz et al. 2015). Monastic debate is similar to this open monitoring practice in that one of its goals is also breaking down the barriers between self and other, albeit through methods that involve logic and reason instead of open awareness meditation (van Vugt et al. 2019). It may therefore be the case that the baseline state of accomplish debate practitioners have higher long-range gamma synchrony as well. Unfortunately, it was not possible to examine gamma power in this study, because the gamma band was filtered out in an effort to reduce movement artifacts.

Some studies show that alpha power increases during meditation, which has been interpreted as increases in relaxation (Cahn and Polich 2006). Since its vigorous nature makes it unlikely that monastic debate is associated with increases in relaxation, the presented analyses do not examine withinindividual alpha power. 


\section{Limitations and Future Research}

Although the findings provide interesting new insights into the nature of monastic debate and the functional role of inter-brain synchrony, it is necessary to acknowledge several limitations. In the naturalistic setting in which EEG was applied, a worry may be the possibility of contamination of the EEG with movement artifacts. In contrast to classical EEG, which is done in a shielded laboratory in which participants sit very still, in this study, EEG was recorded from moving and speaking participants in a Tibetan monastery in India without any shielding. To minimize this problem, active electrodes were used. Previous work has shown that active electrodes significantly reduce artifacts associated with power line interference and motion artifacts (Patki et al. 2012). Similarly, Nathan and Contreras-Vidal (2016) demonstrated that in a system very similar to the studies reported here, very few motion artifacts from walking could be detected. In addition, the comparisons made in this article are mostly within-dyad, which means that both of the processes being compared are similarly affected by artifacts. It remains possible that the increase in mid-frontal theta is driven by motion, because motion tended to increase over the course of the debate, but this is unlikely because motion is typically associated with activity in the beta and gamma bands (Ball et al. 2008). Furthermore, it remains possible that inter-brain synchrony is confounded with speech artifacts, but this is unlikely given that it is unlikely a difference in the amount of speech between the agreement and disagreement epochs.

Another challenge for the studies reported here is that they focus on neural measures without direct behavioral assessments. Consequently, it is not sure that, for example, midfrontal theta reflects absorption, as it has been interpreted here. In fact, some have suggested that mid-frontal theta oscillations reflect fatigue rather than cognitive control and absorption (Kamzanova et al. 2011). However, the studies in which midfrontal theta is seen as a consequence of fatigue describe stimulus-evoked theta. Wascher et al. (2014) showed that while stimulus-evoked theta increased with increasing fatigue over a 4-h task, induced theta, which is more similar to the measure used here, decreased during the same period. Yet another interpretation of the mid-frontal theta effects is that they reflect larger effort engaged in by the experienced monastics. It is possible that rather than reflecting higher skill of experienced monastics in focusing their attention, these findings could reflect a higher level of effort exerted in the debate (Smit et al. 2005). Such higher effort could either reflect more difficulty with debating, which is unlikely for more experienced monastics. Another possibility is that it reflects a voluntary choice to engage in a more complex debate on the topic, for example, by making use of more different sources. Finally, a third possibility is that it reflects the depletion of attention (Schmeichel 2007) as working memory load builds up during the debate. When asked, monastics never report such feelings of depletion after our 10-15-min debates, and in regular debating sessions, they typically continue debating for many hours. Nevertheless, future work could combine the EEG with innovative task-based measures to obtain higher certainty about the psychological correlates of the observed EEG states.

Another limitation of the current study is that many of the comparisons are based on experience - the effect of debate training was inferred from a comparison between more and less-experienced monks. However, experience in monastic debate is also correlated with experience with monastic life. At this point it is not possible to say with certainty that any of the changes observed with experience are due to experience in debate, or that they instead reflect experience with monastic life in general. Most likely, the social setting of the Tibetan monastery in itself also has strong effects on emotion regulation and cognitive processes, even when the monks do not debate. Future research should attempt to disentangle those factors.

A final concern is that a significant correlation between midfrontal theta activity and inter-brain alpha synchrony was observed only in one of the studies - the study that was least controlled. One difference between the two studies is that Study 1 consisted only of logic debates, while Study 2 consisted of both logic and counting debates. However, even when considering the counting and logic debates separately, there was still no correlation between mid-frontal theta and inter-brain synchronization. This discrepancy across the two studies suggests that either there is a ceiling effect for mid-frontal theta in Study 2, or that the observed correlation in Study 1 is a chance fluctuation.

Given that this is an initial study examining the neural correlates of monastic debate, it is only a starting point. Since it is a cross-sectional study, it is not possible to know with certainty whether the difference in increase of midfrontal theta with experience is a result of monastic debate practice, or whether instead this difference between beginner and experienced monastics reflects pre-existing differences between these groups of monastics. Future research should engage in a longitudinal study to verify whether the midfrontal theta slope increases over the course of debate training. Even if it was possible to show such an increase, one cannot easily conclude that the increase is directly due to debate or instead reflects general monastic experience. One possible way to disentangle these possibilities may be to compare monastic's debate to the debate of school children at Tibetan schools that have started to incorporate monastic debate in their curriculum (MacPherson 2000). Yet, given the relatively limited experience that such children have, that can only elucidate the effects of the beginning years of learning debate. Another important direction for future work is to decompose the practice of debate into more detailed components and create theoretical models of this practice. For example, it is worthwhile investigating the role of memory in debating. Specifically, how does the ability to recall information affect 
the debate and its neural correlates? Finally, debate is not practiced for its own sake, but rather, to acquire a deep understanding of Buddhist philosophy and its implications in all aspects of life. It is therefore important to investigate how the neural correlates of debate that are reported in this work affect the quality of debate and the outcomes of the debate. A particularly interesting empirical question is whether selfreported new insights are associated with the neural signature of "aha" moments (Kounios and Beeman 2009).

In conclusion, the data presented here demonstrate how the dyadic practice of analytical meditation is associated with increases in frontal alpha synchrony between two individuals when those individuals are agreeing on a set of tenets compared with when there is some disagreement. In addition, monastic debate is associated with increases in a neural index of mental absorption: mid-frontal theta activity. These findings are a good starting point for further investigating this form of analytical meditation and more clearly delineating where and when it differs from other forms of meditation. In addition, these findings expand on possible roles for inter-brain synchrony by extending it to a global state of being on the same page (metaphorically speaking). Future research should investigate how monastic debate may lead to mental transformations such as increases in the understanding and memory of the studied texts, or more globally to improvements in mental well-being.

Funding Information This work was made possible with generous support from the Hershey Family Foundation, the Sager Family Foundation, and Science for Monks. It was performed in close collaboration with the monastics from Sera Jey Monastery, Bylakuppe, India. Dr. Fresco was supported by NHLBI Grant R01HL119977, NCCIH Grant R61AT009867, NIMH Grant R01MH118218, and NICHD Grant R21HD095099.

Data Availability Preprocessed EEG data can be downloaded here: https://unishare.nl/index.php/s/D3e6DMXzOLAldNO (Study 1) and here https://unishare.nl/index.php/s/1UYBgoG7tF2xfqG (Study 2).

Scripts used for data analysis can be downloaded here: https:// unishare.nl/index.php/s/NbWJepzXM3aDLCX

\section{Compliance with Ethical Standards}

Ethical Approval All procedures performed in studies involving human participants were in accordance with the ethical standards of the institutional and/or national research committee and with the 1964 Helsinki declaration and its later amendments or comparable ethical standards. The study protocol was approved by the Research Ethics Committee of the Faculty of Arts of the University of Groningen (CETO), protocol number 70890721.

Informed Consent Oral informed consent was obtained from all individual participants included in the study. We chose to not use written informed consent because this would be very unfamiliar and anxietyprovoking in this culture that is mainly oral. It was emphasized that the participants could leave the study at any time if they desired to do so, without any adverse consequences to them.
Conflict of Interest The authors declare that they have no conflict of interest.

Open Access This article is licensed under a Creative Commons Attribution 4.0 International License, which permits use, sharing, adaptation, distribution and reproduction in any medium or format, as long as you give appropriate credit to the original author(s) and the source, provide a link to the Creative Commons licence, and indicate if changes were made. The images or other third party material in this article are included in the article's Creative Commons licence, unless indicated otherwise in a credit line to the material. If material is not included in the article's Creative Commons licence and your intended use is not permitted by statutory regulation or exceeds the permitted use, you will need to obtain permission directly from the copyright holder. To view a copy of this licence, visit http://creativecommons.org/licenses/by/4.0/.

\section{References}

Aftanas, L. I., \& Golocheikine, S. A. (2001). Human anterior and frontal midline theta and lower alpha reflect emotionally positive state and internalized attention: high-resolution EEG investigation of meditation. Neuroscience Letters, 310, 57-60.

Astolfi, L., Toppi, J., Borghini, G., Vecchiato, G., Isabella, R., Fallani, F. D. V., et al. (2011). Study of the functional hyperconnectivity between couples of pilots during flight simulation: an EEG hyperscanning study, 2338-2341. https://doi.org/10.1109/IEMBS. 2011.6090654.

Baayen, R. H., Davidson, D. J., \& Bates, D. M. (2008). Mixed-effects modeling with crossed random effects for subjects and items. Journal of Memory and Language, 59(4), 390-412. https://doi. org/10.1016/j.jml.2007.12.005.

Babiloni, F., Astolfi, L., Cincotti, F., Mattia, D., Tocci, A., Tarantino, A., et al. (2007). Cortical activity and connectivity of human brain during the prisoner's dilemma: an EEG hyperscanning study, 49534956. https://doi.org/10.1109/IEMBS.2007.4353452.

Ball, T., Demandt, E., Mutschler, I., Neitzel, E., Mehring, C., Vogt, K., et al. (2008). Movement related activity in the high gamma range of the human EEG. NeuroImage, 41(2), 302-310. https://doi.org/10. 1016/j.neuroimage.2008.02.032.

Bauer, M., Oostenveld, R., Peeters, M., \& Fries, P. (2006). Tactile spatial attention enhances gamma-band activity in somatosensory cortex and reduces low-frequency activity in parieto-occipital areas. Journal of Neuroscience, 26(2), 490-501.

Bolker, B. M., Brooks, M. E., Clark, C. J., Geange, S. W., Poulsen, J. R., Stevens, M. H. H., \& White, J.-S. S. (2009). Generalized linear mixed models: a practical guide for ecology and evolution. Trends in Ecology \& Evolution, 24(3), 127-135. https://doi.org/10.1016/j. tree.2008.10.008.

Braboszcz, C., \& Delorme, A. (2011). Lost in thoughts: neural markers of low alertness during mind wandering. NeuroImage, 54(4), 3040 3047. https://doi.org/10.1016/j.neuroimage.2010.10.008.

Brandmeyer, T., \& Delorme, A. (2018). Reduced mind wandering in experienced meditators and associated EEG correlates. Experimental Brain Research, 236(9), 2519-2528. https://doi.org/ 10.1007/s00221-016-4811-5.

Brovelli, A., Ding, M., Ledberg, A., Chen, Y., Nakamura, R., \& Bressler, S. (2004). Beta oscillations in a large-scale sensorimotor cortical network: directional influences revealed by Granger causality. Proceedings of the National Academy of Sciences, (USA), 101(26), 9849-9854.

Buzsáki, G. (2006). Rhythms of the brain. New York: Oxford University Press. 
Cahn, B. R., \& Polich, J. (2006). Meditation states and traits: EEG, ERP, and neuroimaging studies. Psychological Bulletin, 132(2), 180-211. https://doi.org/10.1037/0033-2909.132.2.180.

Cavanagh, J., Frank, M. J., Klein, T. J., \& Allen, J. J. B. (2010). Frontal theta links prediction errors to behavioral adaptation in reinforcement learning. Neurolmage, 49, 3198-3209.

Clayton, M. S., Yeung, N., \& Cohen Kadosh, R. (2015). The roles of cortical oscillations in sustained attention. Trends in Cognitive Sciences, 19(4), 188-195. https://doi.org/10.1016/j.tics.2015.02. 004.

Cohen, M. X. (2014). Analyzing neural time series data: theory and practice. MIT Press.

Cummins, T., \& Finnegan, S. (2007). Theta power is reduced in healthy cognitive aging. International Journal of Psychophysiology, 66, 10 17.

Dahl, C. J., Lutz, A., \& Davidson, R. J. (2015). Reconstructing and deconstructing the self: cognitive mechanisms in meditation practice. Trends in Cognitive Sciences, 19(9), 515-523. https://doi.org/ 10.1016/j.tics.2015.07.001

Desbordes, G., Negi, L. T., Pace, T. W. W., Wallace, B. A., Raison, C. L., \& Schwartz, E. L. (2012). Effects of mindful-attention and compassion meditation training on amygdala response to emotional stimuli in an ordinary, non-meditative state. Frontiers in Human Neuroscience, 6. https://doi.org/10.3389/fnhum.2012.00292.

Dikker, S., Wan, L., Davidesco, I., Kaggen, L., Oostrik, M., McClintock, J., et al. (2017). Brain-to-brain synchrony tracks real-world dynamic group interactions in the classroom. Current Biology, 27, 1-6. https://doi.org/10.1016/j.cub.2017.04.002.

Doppelmayr, M., Finkenzeller, T., \& Sauseng, P. (2008). Frontal midline theta in the pre-shot phase of rifle shooting: differences between experts and novices. Neuropsychologia, 46(5), 1463-1467. https:// doi.org/10.1016/j.neuropsychologia.2007.12.026.

Dreyfus, G. (2003). The sound of two hands clapping: the education of a Tibetan Buddhist monk. University of California Press.

Dumas, G., Nadel, J., Soussignan, R., Martinerie, J., \& Garnero, L. (2010). Inter-brain synchronization during social interaction. PLoS One, 5(8), e12166. https://doi.org/10.1371/journal.pone.0012166.

Engert, V., Kok, B. E., Papassotiriou, I., Chrousos, G. P., \& Singer, T. (2017). Specific reduction in cortisol stress reactivity after social but not attention-based mental training. Science Advances, 3(10), e1700495. https://doi.org/10.1126/sciadv.1700495.

Friard, O., \& Gamba, M. (2016). BORIS: a free, versatile open-source event-logging software for video/audio coding and live observations. Methods in Ecology and Evolution, 7(11), 1325-1330. https://doi.org/10.1111/2041-210X.12584.

Fucci, E., Abdoun, O., Caclin, A., Francis, A., Dunne, J. D., Ricard, M., et al. (2018). Differential effects of non-dual and focused attention meditations on the formation of automatic perceptual habits in expert practitioners. Neuropsychologia, 119, 92-100. https://doi.org/ 10.1016/j.neuropsychologia.2018.07.025.

Händel, B. F., Haarmeier, T., \& Jensen, O. (2010). Alpha oscillations correlate with the successful inhibition of unattended stimuli. Journal of Cognitive Neuroscience, 23(9), 2494-2502. https://doi. org/10.1162/jocn.2010.21557.

Hoogenboom, N., Schoffelen, J. M., Oostenveld, R., Parkes, L. M., \& Fries, P. (2006). Localizing human visual gamma-band activity in frequency, time and space. NeuroImage, 29(3), 764-773.

Irrmischer, M., Houtman, S. J., Mansvelder, H. D., Tremmel, M., Ott, U., \& Linkenkaer-Hansen, K. (2018). Controlling the temporal structure of brain oscillations by focused attention meditation. Human Brain Mapping, 39(4), 1825-1838. https://doi.org/10.1002/hbm.23971.

Ishihara, T., \& Yoshii, N. (1972). Multivariate analytic study of EEG and mental activity in juvenile delinquents. Electroencephalography and Clinical Neurophysiology, 33, 71-80.

Ishii, R., Shinosaki, K., Ukai, S., Inouye, T., Ishihara, T., Yoshimine, T., et al. (1999). Medial prefrontal cortex generates frontal midline theta rhythm. NeuroReport, 10(4), 675-679. https://doi.org/10.1097/ 00001756-199903170-00003.

Ishii, R., Canuet, L., Ishihara, T., Aoki, Y., Ikeda, S., Hata, M., et al. (2014). Frontal midline theta rhythm and gamma power changes during focused attention on mental calculation: an MEG beamformer analysis. Frontiers in Human Neuroscience, 8, 406. https://doi.org/10.3389/fnhum.2014.00406.

Jeffreys, H. (1998). The theory of probability. Oxford: Oxford University Press.

Josipovic, Z. (2014). Neural correlates of nondual awareness in meditation. Annals of the New York Academy of Sciences, 1307(1), 9-18. https://doi.org/10.1111/nyas.12261.

Kabat-Zinn, J. (2003). Mindfulness-based interventions in context: past, present and future. Clinical Psychology: Science and Practice, 10(2), 144-156.

Kamzanova, A. T., Matthews, G., Kustubayeva, A. M., \& Jakupov, S. M. (2011). EEG indices to time-on-task effects and to a workload manipulation (cueing). World Academy of Science, Engineering and Technology, 80, 19-22 Retrieved from Scopus.

Kardos, Z., Tóth, B., Boha, R., File, B., \& Molnár, M. (2014). Agerelated changes of frontal-midline theta is predictive of efficient memory maintenance. Neuroscience, 273, 152-162. https://doi. org/10.1016/j.neuroscience.2014.04.071.

Ki, J. J., Kelly, S. P., \& Parra, L. C. (2016). Attention strongly modulates reliability of neural responses to naturalistic narrative stimuli. Journal of Neuroscience, 36(10), 3092-3101. https://doi.org/10. 1523/JNEUROSCI.2942-15.2016.

Kok, B. E., \& Singer, T. (2017). Effects of contemplative dyads on engagement and perceived social connectedness over 9 months of mental training: a randomized clinical trial. JAMA Psychiatry, 74(2), 126-134. https://doi.org/10.1001/jamapsychiatry.2016.3360.

Konvalinka, I., Bauer, M., Stahlhut, C., Hansen, L. K., Roepstorff, A., \& Frith, C. D. (2014). Frontal alpha oscillations distinguish leaders from followers: multivariate decoding of mutually interacting brains. NeuroImage, 94, 79-88. https://doi.org/10.1016/j. neuroimage.2014.03.003.

Koole, S. L., \& Tschacher, W. (2017). Synchrony in psychotherapy: a review and an integrative framework for the therapeutic alliance. Frontiers in Psychology, 7, 862. https://doi.org/10.3389/fpsyg. 2016.00862.

Kounios, J., \& Beeman, M. (2009). The Aha! moment: the cognitive neuroscience of insight. Current Directions in Psychological Science, 18(4), 210-216.

Kubota, Y., Sato, W., Toichi, M., Murai, T., Okada, T., Hayashi, A., \& Sengoku, A. (2001). Frontal midline theta rhythm is correlated with cardiac autonomic activities during the performance of an attention demanding meditation procedure. Cognitive Brain Research, 11, 281-287.

Kuyken, W., Hayes, R., Barrett, B., Byng, R., Dalgleish, T., Kessler, D., et al. (2015). Effectiveness and cost-effectiveness of mindfulnessbased cognitive therapy compared with maintenance antidepressant treatment in the prevention of depressive relapse or recurrence (PREVENT): a randomised controlled trial. The Lancet, 386(9988), 63-73. https://doi.org/10.1016/S0140-6736(14)62222-4.

Lachat, F., Hugeville, L., Lemarechal, J.-D., Conty, L., \& George, N. (2012). Oscillatory brain correlates of live joint attention: a dualEEG study. Frontiers in Human Neuroscience, 6, 156. https://doi. org/10.3389/fnhum.2012.00156.

Liberman, K. (2007). Dialectical practice in Tibetan philosophical culture: an ethnomethodological inquiry into formal reasoning. Rowman \& Littlefield Publishers.

Liberman, K. (2015). The logic is made to dance. Rhythm in Tibetan debating. Etnografia e Ricerca Qualitativa, 3. https://doi.org/10. $3240 / 81722$.

Lindenberger, U., Li, S.-C., Gruber, W., \& Müller, V. (2009). Brains swinging in concert: cortical phase synchronization while playing 
guitar. BMC Neuroscience, 10, 22. https://doi.org/10.1186/14712202-10-22.

Lutz, A., Greischar, L. L., Rawlings, N. B., Ricard, M., \& Davidson, R. J. (2004). Long-term meditators self-induce high-amplitude gamma synchrony during mental practice. Proceedings of the National Academy of Sciences, (USA), 101(46), 16369-16373.

Lutz, A., Slagter, H. A., Dunne, J. D., \& Davidson, R. J. (2008). Attention regulation and monitoring in meditation. Trends in Cognitive Sciences, 12(4), 163-169.

Lutz, A., Greischar, L. L., Perlman, D. M., \& Davidson, R. J. (2009). BOLD signal in insula is differentially related to cardiac function during compassion meditation in experts vs. novices. NeuroImage, 47(3), 1038-1046. https://doi.org/10.1016/j.neuroimage.2009.04. 081.

Lutz, A., Jha, A. P., Dunne, J. D., \& Saron, C. D. (2015). Investigating the phenomenological matrix of mindfulness-related practices from a neurocognitive perspective. The American Psychologist, 70(7), 632-658. https://doi.org/10.1037/a0039585.

MacPherson, S. (2000). A path of learning: Indo-Tibetan Buddhism as education (University of British Columbia). https://doi.org/10. 14288/1.0055009.

Makeig, S., \& Jung, T. P. (1995). Changes in alertness are a principal component of variance in the EEG spectrum. NeuroReport, 7(1), 213-216.

Morey, R. D., \& Rouder, J. N. (2018). BayesFactor: computation of Bayes factors for common designs. Retrieved from https:/CRAN. R-project.org/package $=$ BayesFactor.

Müller, V., Sänger, J., \& Lindenberger, U. (2013). Intra- and inter-brain synchronization during musical improvisation on the guitar. PLoS One, 8(9), e73852. https://doi.org/10.1371/journal.pone.0073852.

Nathan, K., \& Contreras-Vidal, J. L. (2016). Negligible motion artifacts in scalp electroencephalography (EEG) during treadmill walking. Frontiers in Human Neuroscience, 9, 708. https://doi.org/10.3389/ fnhum.2015.00708.

Oostenveld, R., Fries, P., Maris, E., \& Schoffelen, J. M. (2011). FieldTrip: open source software for advanced analysis of MEG, EEG, and invasive electrophysiological data. Computational Intelligence and Neuroscience, 2011, 156869. https://doi.org/10.1155/2011/156869.

Pace, T. W. W., Negi, L. T., Dodson-Lavelle, B., Ozawa-de Silva, B., Reddy, S. D., Cole, S. P., et al. (2013). Engagement with cognitively-based compassion training is associated with reduced salivary C-reactive protein from before to after training in foster care program adolescents. Psychoneuroendocrinology, 38(2), 294-299. https://doi.org/10.1016/j.psyneuen.2012.05.019.

Patki, S., Grundlehner, B., Verwegen, A., Mitra, S., Xu, J., Matsumoto, A., ... Penders, J. (2012). Wireless EEG system with real time impedance monitoring and active electrodes. Biomedical Circuits and Systems Conference (BioCAS), 2012 IEEE, 108-111. IEEE.

Perdue, D. (1992). Debate in Tibetan Buddhism. Snow Lion Publications.

Perdue, D. (2014). The course in Buddhist reasoning and debate: an Asian approach to analytical thinking drawn from Indian and Tibetan sources. Boston; London: Snow Lion.

Pfurtscheller, G., \& Lopes Da Silva, F. H. (1999). Event-related EEG/ MEG synchronization and desynchronization: Basic principles. Clinical Neurophysiology, 110(11), 1842-1857. https://doi.org/10. 1016/S1388-2457(99)00141-8.
Pfurtscheller, G., Stancák, A., \& Neuper, C. (1996). Event-related synchronization (ERS) in the alpha band - an electrophysiological correlate of cortical idling: a review. International Journal of Psychophysiology, 24(1), 39-46. https://doi.org/10.1016/S01678760(96)00066-9.

Pinheiro, J., \& Bates, D. (2009). Mixed-effects models in S and S-PLUS. Springer.

Schmeichel, B. J. (2007). Attention control, memory updating, and emotion regulation temporarily reduce the capacity for executive control. Journal of Experimental Psychology General, 136(2), 241-255. https://doi.org/10.1037/0096-3445.136.2.241.

Sederberg, P. B., Kahana, M. J., Howard, M. W., Donner, E. J., \& Madsen, J. R. (2003). Theta and gamma oscillations during encoding predict subsequent recall. Journal of Neuroscience, 23(34), 10809-10814.

Smit, A. S., Eling, P. A. T. M., Hopman, M. T., \& Coenen, A. M. L. (2005). Mental and physical effort affect vigilance differently. International Journal of Psychophysiology, 57(3), 211-217. https://doi.org/10.1016/j.ijpsycho.2005.02.001.

Toppi, J., Borghini, G., Petti, M., He, E. J., Giusti, V. D., He, B., et al. (2016). Investigating cooperative behavior in ecological settings: an EEG hyperscanning study. PLoS One, 11(4), e0154236. https://doi. org/10.1371/journal.pone.0154236.

Tóth, B., Kardos, Z., File, B., Boha, R., Stam, C. J., \& Molnár, M. (2014). Frontal midline theta connectivity is related to efficiency of WM maintenance and is affected by aging. Neurobiology of Learning and Memory, 114, 58-69. https://doi.org/10.1016/j.nlm.2014.04. 009.

van de Vijver, I., Cohen, M. X., \& Ridderinkhof, K. R. (2014). Aging affects medial but not anterior frontal learning-related theta oscillations. Neurobiology of Aging, 35(3), 692-704. https://doi.org/10. 1016/j.neurobiolaging.2013.09.006.

van Vugt, M. K., Sederberg, P. B., \& Kahana, M. J. (2007). Comparison of spectral analysis methods for characterizing brain oscillations. Journal of Neuroscience Methods, 162(1-2), 49-63.

van Vugt, M. K., Simen, P., Nystrom, L., Holmes, P., \& Cohen, J. D. (2012). EEG oscillations reveal neural correlates of evidence accumulation. Frontiers in Human Neuroscience, 6, 106

van Vugt, M. K., Moye, A., Pollock, J., Johnson, B., Bonn-Miller, M., Gyatso, K., et al. (2019). Tibetan Buddhist monastic debate: psychological and neuroscientific analysis of a reasoning-based analytical meditation practice. Progress in Brain Research, 422, 233-253. https://doi.org/10.1016/bs.pbr.2018.10.018.

Wagenmakers, E.-J., Love, J., Marsman, M., Jamil, T., Ly, A., Verhagen, J., et al. (2017). Bayesian inference for psychology. Part II: Example applications with JASP. Psychonomic Bulletin \& Review, 25, 58-76. https://doi.org/10.3758/s13423-017-1323-7.

Wascher, E., Rasch, B., Sänger, J., Hoffmann, S., Schneider, D., Rinkenauer, G., et al. (2014). Frontal theta activity reflects distinct aspects of mental fatigue. Biological Psychology, 96, 57-65. https:// doi.org/10.1016/j.biopsycho.2013.11.010.

Publisher's Note Springer Nature remains neutral with regard to jurisdictional claims in published maps and institutional affiliations. 